\title{
Extraction of self-expanding metallic common bile duct stents with snare and Soehendra lithotripter
}

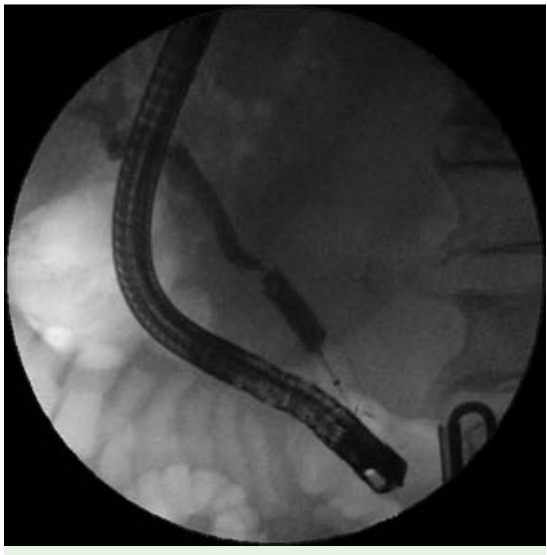

Fig. 1 Stenosis by tumor ingrowth, shown by contrast medium injection.

Self-expanding metallic stents (SEMS) are commonly used for palliation in patients with obstruction of the bile duct. Extraction of SEMS when they become occluded is difficult, sometimes even impossible [1-4]. We describe a new extraction method used in two patients.

The first was a 74-year-old man presenting with jaundice due to pancreatic adenocarcinoma. Endoscopic retrograde cholangiopancreatography (ERCP) showed stenosis of the common bile duct. A partially covered 6-cm SEMS (Taewoong Medical, Seoul, Korea) was placed. Ten months later the patient presented with septic fever but no jaundice. ERCP showed partial occlusion of the SEMS at the proximal noncovered end by ingrowth of tumor tissue (๑ Fig. 1).

Attempted extraction of the stent with a polypectomy snare (Cook Medical; Cook Ireland Ltd., Limerick, Ireland) failed even using maximum tensile force.

Our second patient was a 48-year-old woman with radiological diagnosis (CT, magnetic resonance cholangiopancreatography) of a choledochal cyst. ERCP revealed cystic dilatation of the common bile duct, measuring $7 \mathrm{~cm}$ in diameter, and a distal stenosis. A 6-cm SEMS (Taewoong Medical) was placed. On days 64 and 66 after stent placement, extraction of the SEMS was attempted because of occlusion, but failed to be achieved using basket, grasper, or snare.

In both cases of unextractable SEMS we performed a new technique: the SEMS

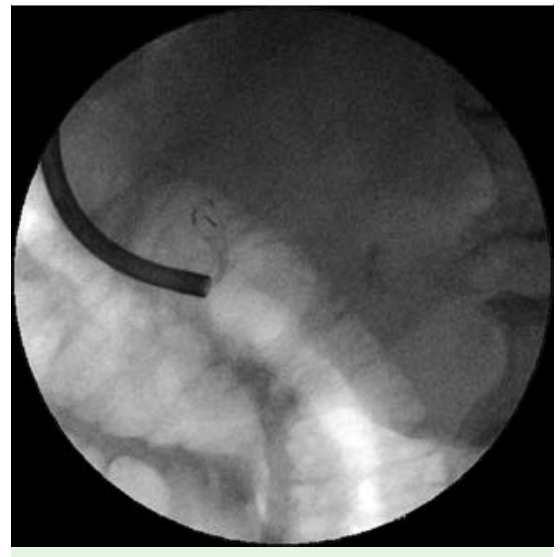

Fig. 2 Insertion of the metal sheath of Soehendra's extractor.

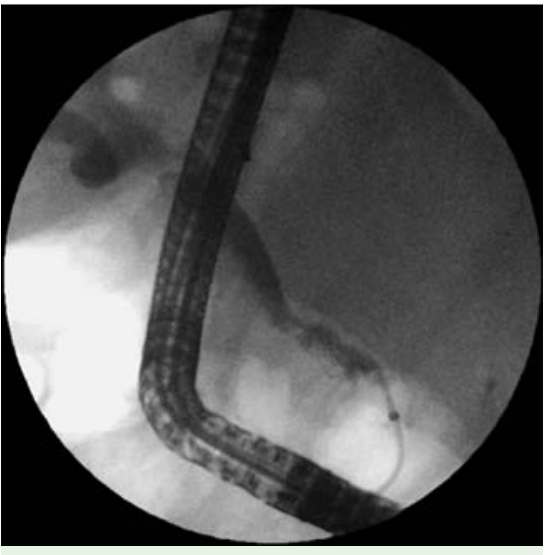

Fig. 3 Contrast medium injection after extraction.

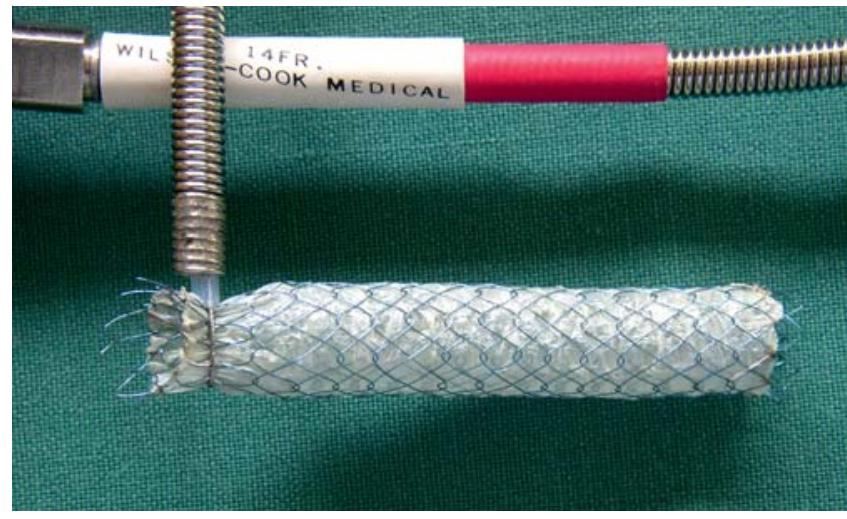

Fig. 4 Capturing the stent by the snare inside the metal sheath of Soehendra's extractor.

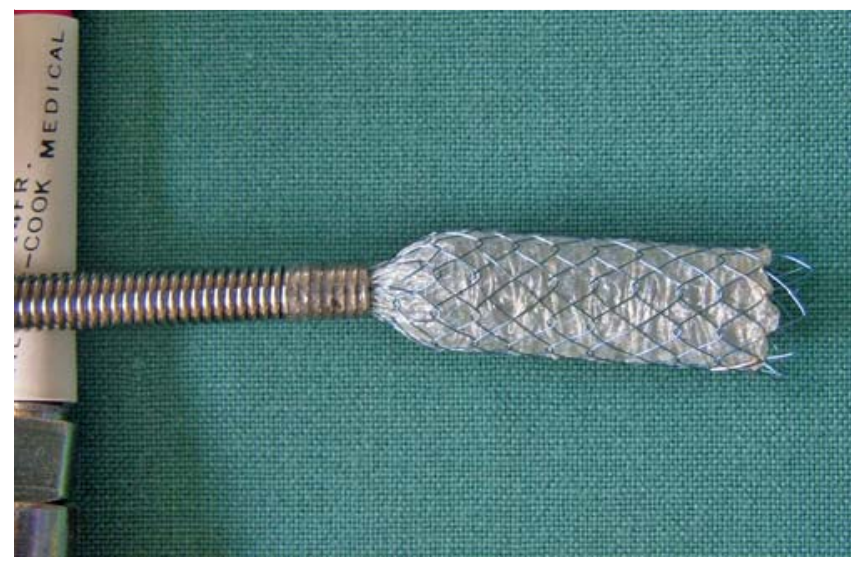

Fig. 5 Pulling the stent into the metal sheath of Soehendra's extractor.

was caught with a polypectomy snare (Cook Medical, $15 \times 25 \mathrm{~mm}$ ) at the free duodenal end. The endoscope was removed and the metal sheath of the Soehendra emergency lithotripter (Cook Medical) was inserted over the polypectomy snare as it is usually inserted over the
Dormia basket in lithotripsy. The mechanical lithotripter was then connected and the hydraulic crank slowly wound, moving the metal sheath forward as a wedge between the common bile duct wall and the SEMS ( $\bullet$ Fig. 2). 
The situation after extraction of the stent is shown in Fig. 3.

- Figs. 4 and 5 give a schematic demonstration of the technique.

This technique allowed us to extract the "unextractable" stents in both patients without any problems.

\section{Competing interests: None}

Endoscopy_UCTN_Code_TTT_1AR_2AZ

\section{P. M. Heinerman, J. Holzinger}

Department of Interventional Endoscopy, Paracelsus Medical Private University,

Salzburg, Austria

\section{References}

1 Shin HP, Kim MH, Jung SW et al. Endoscopic removal of biliary self-expandable metallic stents: a prospective study. Endoscopy 2006; 38: 1250-1255

2 Familiari P, Bulajic M, Mutignani M et al. Endoscopic removal of malfunctioning biliary self-expandable metallic stents. Gastrointest Endosc 2005; 62: $903-910$

3 Bueno JT, Gerdes H, Kurtz RC. Endoscopic management of occluded biliary Wallstents: a cancer center experience. Gastrointest Endosc 2003; 58: 879-884

4 Kahaleh M, Tokar J, Le T, Yeaton P. Removal of self-expandable metallic Wallstents. Gastrointest Endosc 2004; 60: 640-644
Bibliography

DOI $10.1055 / \mathrm{s}-0030-1255790$

Endoscopy 2010; 42: E300 - E301

(c) Georg Thieme Verlag KG Stuttgart · New York . ISSN 0013-726X

\section{Corresponding author}

\section{P. M. Heinerman, MD}

Department of Interventional Endoscopy Paracelsus Medical Private University

Müllner Hauptstr. 48

5020 Salzburg

Austria

Fax: +43-662-448254008

p.heinerman@salk.at 